\title{
Determinants of Interface Criteria Learning Technology for Disabled Learner using Analytical Hierarchy Process
}

\author{
Syazwani Ramli ${ }^{1}$, Hazura Mohamed ${ }^{2}$, Zurina Muda ${ }^{3}$ \\ Faculty of Information Science \& Technology \\ Universiti Kebangsaan Malaysia (UKM) \\ 43600 Bangi, Selangor
}

\begin{abstract}
The advancement of technology nowadays is rapidly increasing due to the leveraging availability of learning technology. Due to the rapid change in the availability of technology, it is crucial for disabled learners to select a good technology design that may help them to achieve better academic achievements. Selecting a good design of technology involves a decision making process to choose several designs of learning technology. In general, the abilities, capacities and achievements of disabled learners are lower compared to a normal child. Using a good approach and assisted with the right selection of learning technology may help disabled learners to get a better understanding and achievement in academic matters. In this study, the analytical hierarchy process (AHP) approach was used to determine the best appropriate design of learning technology for disabled learners. Three hierarchy levels made up of criteria, sub-criteria and alternatives were considered. This study finds the best selection design of elements that can be used in the development of learning technology in a classroom of disabled learners.
\end{abstract}

Keywords-Selection design; learning technology; disabled learner; decision making; Analytical Hierarchy Process (AHP)

\section{INTRODUCTION}

In this sophisticated era of technology, the availability of technology may help human in many aspects in life especially in education field. In general, the suitability of technology is the main concern for adaptability of human aspects especially for disabled learner. As we known, disabled learner has a limitations and capacity compared to as a normal learner. Disabled learner needs a certain approach, design and methods to adapt on their capability especially in the usage of a technology.

The technology not only focusing on certain area content of teaching aspect but also need to focus on the limitations and difficulties that disabled learner has [1]. Lack accessing appropriate of technology and unsuitable design of website and online learning may become disadvantage to disabled learner [2]. It is shown that suitability aspect of design technology learning need to be considered as a crucial part for development of learning technology for disabled learner.

In the $21^{\text {st }}$ century technology nowadays, technology may provide in assisting disabled learner to help them understand on their learning process. Evolutions development of information technology sector is one of component in $21^{\text {st }}$ century. In the $21^{\text {st }}$ century, modes of electronic are emphasize specially for the disabilities student and risk learners [3]. Action and policies should be emphasized to disabled learner in order to make sure they are not being left behind with others in gaining equality in education. As we known that disabled learner has limitations in terms of cognitive level, lack of the physical movement and psychological activity.

Making a decision with the support of family members, ability to speak in English, writing, reading and finding a job is an essential business of an education for disabled learner [4]. Literally, disabled learner should have a good support system to make sure them in a good track especially in process of learning. They need to assist with a right approach and methods in order to attract their attention and having fun in a learning class environment. In designing of an application with accessible functions easy for disabled learner to interact, understand, accomplish some tasks activities and response to the system [5].

Best pedagogical design in assistive technology is one of the crucial issues that might help student with disability and sensory limitation [6]. A best design with their suitability and approaches may help to overcome their limitations and level of capability that they have. Interface design with a right modality and not give a cognitive load functions will ensure disabled learner more understand, receive and process information clearly.

This paper is structured as follows: In Section II, a discussion of the related works is given. Section III describes the methodology followed by results and discussion in Section IV and Section V conclude the study and suggestion for future work.

\section{RELATED WORK}

The decision making process involves a competitive, complex and combative environment [7]. Everyone is a decision maker and making better decisions in life is a practice and skill that we need to consider and develop. Choosing the right criteria for a decision maker is one of the crucial aspects that needs to be analyzed. Accessing the problem and finding the solution through the available alternatives from multiple criteria is one of the multi-criteria decision making approaches (MCDM) [8]. Providing a solution with a variety of alternatives based on the right perspective and tools may help to cater to the problem at hand. 
The variations of technology that are available with sophisticated attributes and dynamic would lead to various solutions for the disabled learner to choose the best assistive technology in terms of adaptability and availability [9]. Certain aspects and approaches would have issues and consideration which should be highlighted in the research based on the adaptability and suitability of technology to a disabled learner user. Based on Assistive Technology Industry Association, assistive technology can be described as a device, apps and principle that may help to enhance everyday life of disability person includes learning and working. [10]. Personalization is one of the main factors that needs to be considered in education as we are aware every learner has differences and this concern is recognized by educators and researchers [11].

Technology innovation is widely expanding in recent development where the gap between innovation and innovative products is reducing [12]. A variety of inventive products are available nowadays but how far does the product have an innovative value to the disabled learner? The attributes character of an innovation learning technology needs to be adapted and accepted by disabled learner users as it can reduce the burden that they carry. A study by Rogers state that the characteristics of innovation may influence the decision maker to adopt or reject the innovation [13].

Multi-criteria decision making (MCDM) has methods that are suitable to evaluate and make decisions by providing the best option of an alternative in order to choose the best criteria that make up the solutions [14]. Every piece of software has a uniqueness of attributes, and each of decision-makers have different point of views towards the attributes, hence the process of selecting the appropriate of software is a difficult task [15].A variety of alternatives is provided which may optimize the solutions and cater to the problem that has arisen. The analytical hierarchy process (AHP) reflects on quantifying and evaluating intangible factors and choices in a multi objective environment and leads to the structuring of a complex structure in a decision making process [16].

A pairwise comparison between the attributes of criteria, sub- criteria and alternatives is the process to evaluate and optimize the solutions in the analytical hierarchy process (AHP). The analytical hierarchy process (AHP) is one of the decision making tools that can determine the importance of criteria and sub-criteria [17]. The formulation of an algorithm from the analytical hierarchy process (AHP) may help the teachers and parents of disabled learners to find the best design of learning technology that suits their children's ability and capacity.

\section{MethodOLOGY}

A survey was conducted in two (2) special schools under the Ministry of Education Malaysia (KPM), located in Johor, Malaysia. The survey was distributed among the school teachers who are the right people involved in the learning process of disabled learners. A total of 30 survey data were collected during the survey process. The main objective of the survey process is to collect feedback based on the suitability design of learning technology that is needed for disabled learners in a classroom learning environment.

\section{A. Overview of AHP Method}

In order to choose the best selection of design learning technology for disabled learners, the following method of flow analytical hierarchy process (AHP) should be considered. The first step in the analytical hierarchy process (AHP) is to define an objective based on the problem that has arisen in the situation. The first level represents an objective or goal, while the second level represents criteria, and the lowest level is alternatives. Once the hierarchy level is formed, the pairwise comparison is compared and analyzed based on each level of hierarchy. The details of process development of hierarchical model are per shown as Fig. 1 while procedure of flowchart of analytical hierarchy process are per shown as Fig. 2.

\section{B. Development of Hierarchy Model}

In this step, the hierarchy model of this study is developed. The three levels of hierarchy model in this study are described as the Fig. 2 as follow

Fig. 2.Design Learning Technology of Disabled Learner [1]

- Overview the situation

- Organize multiple criteria

- Asses multiple criteria

- Evaluate alternatives based on the assescriteria

- Rank alternative

- Comprise the judgment based multiple expert

Fig. 1. Process Development of Hierarchy Model.

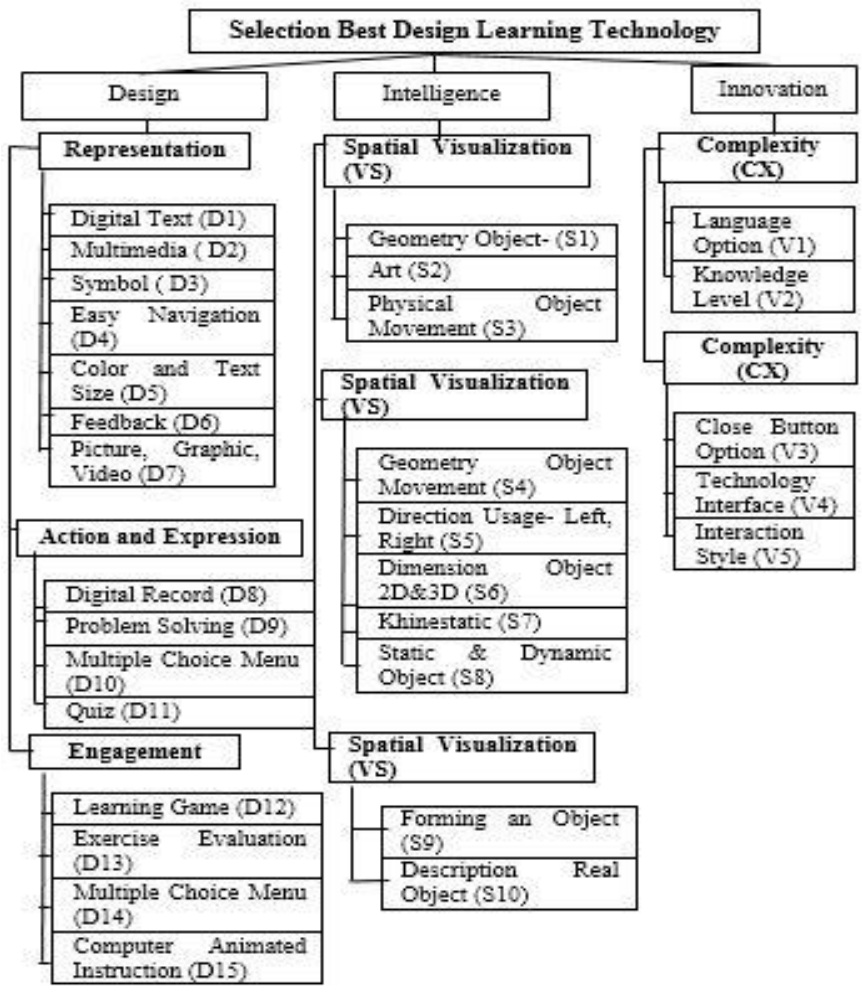

Fig. 2. Flowchart of Analytical Hierarchy Process (AHP) [1]. 


\section{Steps in the Analytical Hierarchy Process (AHP)}

The judgment matrix depends on the availability of the level hierarchy models. The following are the steps taken when applying an analytical hierarchy process (AHP):

a) Firstly, the structure of a hierarchy is based on setting goals that are made up of criteria, sub-criteria and alternatives.

b) Secondly, a pairwise comparison matrix for criteria, sub- criteria and alternatives is constructed as below:

$A=\left[\begin{array}{ccc}a^{11} & a^{12} & a^{1 n} \\ a^{21} & a^{22} & a^{2 n} \\ a^{n 1 n 2} & \ldots \ldots & a^{n n}\end{array}\right]$ $\mathrm{ii}=\mathrm{j}$

Wherein $A_{i j}, i, j=1,2 \ldots \ldots . n, i=$ row, $j=$ column, $\left.A\right|_{j}=1$ for

Based on the equation (1) above, the matrix $A$ has three rows and three columns wherein $a^{l 1}$ represents first row and first column.

$\mathrm{A}_{\mathrm{ij}}=1$ for $\mathrm{ii}=\mathrm{j}$

$\mathrm{A}_{\mathrm{ij}}=\mid \frac{1}{A j i}$ for $\mathrm{i}=\mathrm{j}$

c) Thirdly, the weight for criterion and alternatives selected from the matrix is calculated using the normalization procedure:

Calculation of data per row:

$W i=\sum_{j=1}^{n} a i j, i=1,2, \ldots . n$

$W i$ in the equation (2) above represents the total of the sum of each column wherein $n$ represent column and $\mathrm{j}$ is row $=$ $i+j+n$

Value of weighted normalization:

$W i=\frac{\sum_{j=1}^{n} a i j, i=1,2, \ldots n}{\sum_{k=1}^{n} \sum_{j=1}^{n} a k j}, 1=1,2 \ldots . n$

Equation 3 above shows on how to calculate a priority vector wherein $\sum_{j=1}^{n} a i j$ represents the number of each column is divided by the total of each column that represents by $\sum_{k=1}^{n} \sum_{j=1}^{n} a k j$

Eigen value:

$W i=\frac{1}{n}+(A 1+A 2+A 3+\ldots .+A n)$
Eigenvalue is calculated by equation (4) wherein $(A 1+A 2+A 3+\ldots A n)$ are represented the total row is divided by the value of priority vector $\left(\frac{1}{n}\right)$ and the results of value is formed by the equation (5). Hence, the vector weightage is multiplied by each number of columns and rows as per equation (6) to synthesize the vector weightage.

Vector weighting:

$$
V=\left[V^{1}, V^{2}, \ldots . V^{n}\right]^{T}
$$

Finally the weight of all alternatives are synthesized with the weights obtained for each category as follows:

$$
B x V=\left(\begin{array}{lll}
b^{11} & b^{12} & b^{1 n} \\
b^{21} & b^{22} & b^{2 n} \\
b^{n 1} & b^{n 2} & b m
\end{array}\right)\left(\begin{array}{c}
V^{1} \\
V^{2} \\
V^{n}
\end{array}\right)
$$

Next, the value obtained needs to do a consistency process to determine whether the judgment value obtained is consistent or not. The consistency formula is constructed as per shown in equation (7). After the judgment values obtained, the consistency index as stated as per equation (8) need to be done to determine whether the value is consistence or not, hence the percentage of value of consistency ratio can be obtained as per equation (9).

Maximum Eigen value:

$$
\lambda \max =\frac{1}{n}=\sum_{i=1}^{n} \frac{(A w) i}{w i}
$$

Consistency Index:

$$
C I=\frac{(\pi \max -n)}{n-1}
$$

Consistency Ratio:

$$
\frac{\text { Index Consistency }}{\text { Average }}
$$

$=\frac{(\lambda \max -n)}{r(n-1)} 100 \%$

Saaty states that the acceptable consistency ratio should be less than 0.10 and that even a ratio obtained less than 0.20 is also acceptable [18]. Evaluation of the consistency are generated by decision makers through judgment in pairwise comparison matrices in AHP [19].

\section{RESUlT AND DISCUSSION}

\section{A. Perform Pairwise Comparisons for all Levels}

The pairwise comparisons depend on the level of hierarchy of the elements. The pairwise comparisons in this study consist of criteria elements, sub-criteria elements and alternative elements. The evaluations of the pairwise comparisons for 
criteria are shown in Table I and the evaluations of the pairwise comparisons for sub-criteria elements are shown in Table II.

Table I shows the pairwise comparisons for all criteria that consist of learning design, intelligence, and innovation. The results show that design obtained the highest priority vector of 0.65 , followed by intelligence $(0.25)$ and innovation $(0.10)$. Table II shows the pairwise comparisons of all sub-criteria that consist of representation, action and expression, engagement, spatial visualization, spatial relation, spatial orientation, complexity, and compatibility. The results show that representation obtained the highest priority vector of 0.57 , followed by action and expression at 0.29 , and engagement at 0.14 for the design sub-criteria. For the intelligence criteria, the highest alternative obtained from the pairwise comparison was spatial visualization at 0.61 , followed by spatial relation at 0.27 and spatial orientation at 0.12 . The complexity sub-criteria obtained a higher priority vector of 0.75 , followed by compatibility at 0.25 from the results of the pairwise and synthesize comparisons.

\section{B. Overall Priority Vector for all hierarchy}

The following are the details of all combinations of priority vector, new vector, consistency index (CI), and consistency ratio (CR) obtained that consist of elements of criteria and subcriteria, as shown in Table 3. If the value of consistency ratio (CR) is less than $0.1 \leq 0.2$, the evaluation is acceptable. Otherwise, if the value of consistency ratio (CR) obtained is more than 0.2 , the judgment value needs to be revised by the decision maker until the value obtained is an acceptable value. Table III shows the results of all priority vectors for sub criteria that were obtained meanwhile Table IV shows the value of Random Index (RI) based on the number of judgments.

\section{Develop Priority Ranking for All Hierarchy}

The results of priority ranking for all hierarchies were developed based on the weightage value of the priority vector. To generate a final priority vector is by multiplying the priority vector of criteria by priority vector of each alternative of an objective [20]. Based on the pairwise and synthesizing matrix results, the overall priority vector for all hierarchies was obtained. The overall priority vector can be obtained by multiplying the priority vector of criteria with the priority vector of sub-criteria and alternatives. The calculation to obtain the overall priority vector is as follows:

(0.65) $(0.57)=0.37$ wherein 0.65 (Priority Vector) for criteria and 0.57 (Priority Vector) for sub-criteria.

Table $\mathrm{V}$ shows the results obtained from the weightage of priority vector of all criteria and sub-criteria. In this study, the selection of best selection design is based on the results of the higher weightage of priority vector obtained from the synthesizing process. The best design in learning technology is needed to ensure that disabled learners can engage and enhance their performance in academic skills. The availability of technology present nowadays may not all be suitable for a user, especially disabled learners based on their ability and capacity. An innovative approach that integrates with a good and suitable design should be consider in development of learning technology of disabled learner.
TABLE. I. SYNTHESIZING MATRIX FOR ALL CRITERIA

\begin{tabular}{|l|l|l|l|l|}
\hline Goal & D & I & IV & PV \\
\hline Learning Design (D) & 0.69 & 0.69 & 0.69 & 0.69 \\
\hline Intelligence (I) & 0.17 & 0.17 & 0.17 & 0.17 \\
\hline Innovation (IV) & 0.14 & 0.14 & 0.14 & 0.14 \\
\hline
\end{tabular}

TABLE. II. SyNTHESIZING MATRIX FOR ALL SUB-CRITERIA

\begin{tabular}{|l|l|l|l|l|}
\hline Goal & D & I & IV & PV \\
\hline Representation (R) & 0.60 & 0.69 & 0.43 & 0.57 \\
\hline Action and Expression (AE) & 0.20 & 0.23 & 0.43 & 0.29 \\
\hline Engagement (E) & 0.20 & 0.08 & 0.14 & 0.14 \\
\hline Spatial Visulization (SV) & 0.60 & 0.69 & 0.43 & 0.61 \\
\hline Spatial Relation (SR) & 0.20 & 0.23 & 0.43 & 0.27 \\
\hline Spatial Orientation (SO) & 0.20 & 0.08 & 0.14 & 0.12 \\
\hline Complexity & 0.60 & 0.69 & 0.43 & 0.75 \\
\hline Compatibility & 0.20 & 0.23 & 0.43 & 0.25 \\
\hline
\end{tabular}

TABLE. III. All Priority Vectors FOR Sub-CRITERIA [4]

\begin{tabular}{|c|c|c|c|}
\hline Sub Criteria & Wt1 & Wt2 & $\mathrm{C} 1$ \\
\hline \multicolumn{4}{|c|}{ Learning Design (LD) } \\
\hline $\mathrm{R}$ & 0.65 & 0.57 & 0.37 \\
\hline $\mathrm{AE}$ & 0.65 & 0.29 & 0.19 \\
\hline E & 0.65 & 0.14 & 0.10 \\
\hline \multicolumn{4}{|l|}{ Intelligence (I) } \\
\hline SV & 0.25 & 0.61 & 0.15 \\
\hline SR & 0.25 & 0.27 & 0.07 \\
\hline SO & 0.25 & 0.12 & 0.03 \\
\hline \multicolumn{4}{|c|}{ Innovation (IV) } \\
\hline $\mathrm{CX}$ & 0.10 & 0.75 & 0.08 \\
\hline CT & 0.10 & 0.25 & 0.03 \\
\hline
\end{tabular}

TABLE. IV. RANDOM INDEX TABLE [5]

\begin{tabular}{|l|l|l|l|l|l|l|l|l|}
\hline$(\mathrm{n})$ & 1 & 2 & 3 & 4 & 5 & 6 & 7 & 8 \\
\hline$(\mathrm{RI})$ & 0 & 0 & 0.58 & 0.9 & 1.12 & 1.24 & 1.32 & 1.41 \\
\hline
\end{tabular}

TABLE. V. PRIORITY VeCtORS FOR ALl CRITERIA AND SUb-CRITERIA [6]

\begin{tabular}{|l|l|}
\hline Criteria & Priority Vector $(\mathrm{PV})$ \\
\hline D & 0.65 \\
\hline I & 0.25 \\
\hline IV & 0.10 \\
\hline Sub Criteria & Priority Vector $(\mathrm{PV})$ \\
\hline R & 0.57 \\
\hline AE & 0.29 \\
\hline E & 0.14 \\
\hline SV & 0.61 \\
\hline SR & 0.27 \\
\hline SO & 0.12 \\
\hline CX & 0.75 \\
\hline CT & 0.25 \\
\hline
\end{tabular}


TABLE. VI. PRIORITY VeCTORS FOR ALL CRITERIA AND SUB-CRITERIA [6]

\begin{tabular}{|l|l|l|l|}
\hline \multirow{2}{*}{ No } & Criteria & $\begin{array}{l}\text { Important of } \\
\text { Element Interface }\end{array}$ & Weightage \\
\hline \multirow{3}{*}{1} & Learning Design (LD) & Representation (R) & 0.145 \\
\cline { 2 - 4 } & Intelligence (I) & Spatial Visualization (SV) & 0.044 \\
\cline { 2 - 4 } & Innovation (IV) & Complexity (CX) & 0.751 \\
\hline
\end{tabular}

The integration of these three (3) criteria which are learning design, intelligence and innovation may increase and enhance the understanding of learning process of disabled learner. The integration of these criteria may attract the disabled learner to learn in interactive way in the class environment. The strength of disabled learner should be identified and embedded as one of an innovative approach in learning technology. As we've known that disabled learner have deficiency in cognitive level as compared with a normal learner. Hence, a special approach should be integrate with a usages of technology as it may help disabled learner more understands in their learning process.

Table VI shows the result of an importance of an element interface based on the selection of learning technology of disabled learners that consist of learning design, intelligence and innovation. The result shows that D1 has the highest value at 0.145 (representation), D8 with a value of 0.800 (action and expression), and D12 with a value of 0.800 (engagement). For the intelligence concept, the highest value is $\mathrm{S} 1$ with a value of 0.044 (spatial visualization), S4 with a value of 0.008 (spatial relation) and S9 (spatial orientation) with a value of 0.002 . For the innovation concept, $\mathrm{V} 1$ has the highest value at 0.751 (complexity) and V3 with a value of 0.018 (compatibility).

\section{Selection of Best Design for Learning Technology}

The integration of these three concepts that are embedded as a special approach in designing learning technology can enhance the process of learning and attract disabled learners to learn in an interactive environment. The development of learning technology should be emphasized towards the needs of disabled learners based on their ability and capacity. Skills, strengths and abilities of disabled learners should be recognized to determine the best approach to overcome their limitations which at the same time may increase the quality of education for disabled learners.

\section{CONCLUSION}

The availability of learning technology nowadays can enhance and improve the learning process. Hence, the selection of best design of learning technology embedded with the right approach may attract and improve the learning process of disabled learners. The implementation of the analytical hierarchy process (AHP) in decision making may optimize the available alternatives to cater to the problem that has arisen. Based on the results obtained, it shows that learning design (LD) had the highest values obtained in the selection of design that is 0.145 followed by intelligence (I) 0.044 and complexity (CX) 0.751. Hence, these findings show the pilot results of selection determinants of interface criteria of learning technology for disabled learner that will use for developing learning technology of disabled learner. The best design is determined to help developers in developing learning technology for disabled learners that can be used in a classroom environment.

\section{FUTURE WORK}

The authors have discuss on how to optimize the best selection design by using analytical hierarchy process (AHP) approached in selecting the best design of learning technology for disabled learner. But still there is a scope that is no covered yet by these findings hence future work will suggest a new hybrid method to implement and propose the evaluation these final findings of these study. A hybrid method will integrate and use by using different methods which is carried out for future work.

\section{REFERENCES}

[1] Altınay, F., Cagiltay, K., Jemni, M., \&Altınay, Z, "Guest Editorial: Technology Support for Fostering Life-Long Learning of Learners with Disabilities," Educational Technology \& Society, 2016, 19 (1), pp: 1-3.

[2] Pirani,Z and Sasikumar M."Assistive E-learning System for the Learning Disabled,'International Conference on Advanced Computing Technologies and Application, 2015, 45, pp:718-727.

[3] B.H. Benton-Borghi,"A Universally Designed for Learning (UDL) Infused Technological Pedagogical Content Knowledge (TPACK) Practitioners' Model Essential for Teacher Preparation in the 21st Century, J. Educational Computing Research, 2013,48(2), pp:245-265.

[4] Nasir, M.N.A and Efendi A.N.A.E.” Special education for children with disabilities in Malaysia: Progress and obstacles Muhamad Nadhir Abdul Nasir," Geografia-Malaysian Journal of Society and Space 12(10).

[5] FernáNdez-LóPez, Á., RodríGuez-FóRtiz, M. J., RodríGuez-Almendros, M. L., \& MartíNez-Segura, M. J. "Mobile learning technology based on iOS devices to support students with special education needs." Computers \& Education, 2013, 61, 77-90.

[6] Zhuhadar, L., Carson, B., Daday, J., Thrasher, E., \& Nasraoui, O. "Computer-assisted learning based on universal design, multimodal presentation and textual linkage", Journal of the Knowledge Economy,2016. 7(2), 373-387.

[7] Thirumalai, C., \& Senthilkumar, M. "An assessment framework of intuitionistic fuzzy network for C2B decision making. In 2017 4thInternational Conference on Electronics and Communication Systems (ICECS).2017.pp. 164-167.

[8] Wu, H. M., “Online individualised tutor for improving mathematics learning: a cognitive diagnostic model approach".2018.Educational Psychology, 1-15.

[9] Adebisi, R. O., Liman, N. A., \& Longpoe, P. K.," Using Assistive Technology in Teaching Children with Learning Disabilities in the 21st Century".2015. Journal of Education and Practice, 6(24), 14-20.

[10] Taylor, H. (2019). Assistive Technology for Students with Learning Disabilities: Kurzweil 3000. Technology and the Curriculum: Summer 2019.

[11] El Mawas, N., Tal, I., Moldovan, A. N., Bogusevschi, D., Andrews, J., Muntean, G. M., \& Muntean, C. H., "Improving STEM Learning Experience in Primary School by Using NEWTON Project Innovative Technologies". 2018. InInternational Conference on Computer Supported Education. Springer, Cham pp. 214-230.

[12] Wani, TA, Ali, SW, "Innovation Diffusion Theory: Review \& Scope in the Study of Adoption of Smartphones in India," Journal of General Management Research.2015. 3 (2), 101-118.

[13] Rogers, E.M.Diffusion of Innovations, 5th ed.; 2003. The Free Press: New York, NY, USA.

[14] Aziz, N. F., Sorooshian, S., \& Mahmud, F., "MCDM-AHP method in decision makings". ARPN Journal of Engineering and Applied Sciences, 2016.11(11), 7217-7220.

[15] Abdullateef, B. N., Elias, N. F., Mohamed, H., Zaidan, A. A. \& Zaidan, B. B. 2016. An evaluation and selection problems of OSS - LMS packages. SpringerPlus. doi:10.1186/s40064-016-1828-y. 
[16] Ahmad, Mohd Nazri, N. A. Maidin, M. H. A. Rahman a, "Conceptual Design Selection of Manual Wheelchair for Elderly by Analytical Hierarchy Process (AHP) Method: A Case Study, 'International Journal of Applied Engineering Research,2017 vol: 12 (17) pp: 6710-6719.

[17] Cheng, E. W., \& Li, H.,"Analytic hierarchy process: an approach to determine measures for business performance".2001. Measuring business excellence, 5(3), 30-37.
[18] Wedley, W. C., "Consistency prediction for incomplete AHP matrices. Mathematical and Computer Modelling, 199317(4-5), pp:151-161.

[19] Aguar, J. \& Tur, A. 2019. AHP-Group Decision Making Based on Consistency (Ccm). doi:10.3390/math7030242.

[20] Simon, J., Adamu, A., Abdulkadir, A. \& Henry, A. S. 2019. Analytical Hierarchy Process (AHP) Model for Prioritizing Alternative Strategies for Malaria Control 5(1): 1-8. doi:10.9734/AJPAS/2019/v5i130124. 